\title{
A Critique of Wolak's Evaluation of the NZ Electricity Market: Introduction and Overview
}

\author{
Lewis Evans ${ }^{1}$, Seamus Hogan ${ }^{2}$ and Peter Jackson ${ }^{3}$ \\ ${ }^{1}$ New Zealand Institute for the Study of Competition and Regulation, and \\ School of Economics and Finance' Victoria University of Wellington \\ lew.evans@vuw.ac.nz \\ ${ }^{2}$ Corresponding Author \\ Department of Economics and Finance \\ University of Canterbury \\ seamus.hogan@canterbury.ac.nz \\ ${ }^{3}$ Department of Management \\ University of Canterbury \\ prj20@uclive.ac.nz
}

\begin{abstract}
:
This paper is the first in a symposium of papers that examine the 2009 report by Frank Wolak into the New Zealand electricity market. The Wolak report concluded that there had been a cumulative total of $\$ 4.3 b$ (NZD) of overcharging in the New Zealand wholesale market over a period of seven years. In this paper, we introduce the Wolak findings in the context of the salient features of the New Zealand market, and explain that this headline figure is highly sensitive to some (quite unrealistic) assumptions about the structure of this market. The papers that follow this introduction examine Wolak's methodology and its empirical application.
\end{abstract}

Key Words: Wolak Report; electricity markets; market power.

JEL Codes: L41, L13 


\section{A Critique of Wolak's Evaluation of the NZ Electricity Market:}

\section{Part 1: Introduction and Overview}

\section{Introduction.}

In 2009, the Commerce Commission of New Zealand released "An Assessment of the Performance of the New Zealand Wholesale Electricity Market (Wolak, 2009)", a report it had commissioned from Professor Frank Wolak. This report was the result of three years work and was part of an investigation that cost some $\mathrm{NZ} \$ 3.5 \mathrm{~m}$. It analysed the extent to which electricity generators in New Zealand have exercised market power to achieve wholesale electricity prices in excess of the levels that would result from perfect competition. While it found no evidence of affiliated actions, the report concluded that there was evidence that generators have had an incentive to exercise unilateral market power, and evidence that they have exercised that market power. It estimated a counterfactual benchmark of what prices would have been in the absence of market power and used this counterfactual to conclude that there had been a cumulative total of NZ\$4.3b. of overcharging over a period of seven years.

The Wolak report contains three broad strands of empirical evidence that generators have exercised unilateral market power in New Zealand. The first strand uses standard oligopoly theory to calculate from the observed offers the extent to which firms have had the ability and the incentive to exercise unilateral market power. The second strand uses regression analysis to estimate the extent to which those measures of market power can explain the observed price movements in the New Zealand wholesale market. The final strand uses direct estimates of generators' short-run marginal cost curves and assumptions 
about demand to calculate the extent to which market prices have exceeded marginal cost pricing. It is this section of the report that generates the estimate of $\$ 4.3 \mathrm{~b}$. of overcharging.

This headline figure illustrates the potential import of the Wolak report. Not surprisingly, then, this is the part of the report that has received most attention. ${ }^{1}$ In this paper, we summarise and extend various critiques of the method used in developing the counterfactual to show why we believe that $\$ 4.3 \mathrm{~b}$ is an overstatement of the amount of market-power rent earned in the New Zealand wholesale market over the period analysed. The remaining two papers in this symposium consider the other two strands of empirical evidence presented in the Wolak report.

Figure 5.12 in the Wolak report, reproduced below, shows the calculation of the $\$ 4.3 \mathrm{~b}$., which is the sum of the red-shaded bars. These bars depict the total payments made to generators in excess of those that would have been made under a hypothetical benchmark of perfect competition. Total payments to generators are easily observed directly in the available data, but the counterfactual benchmark is not and needs to be inferred from a combination of data and assumptions about the nature of the market.

The bulk of the $\$ 4.3 \mathrm{~b}$ was obtained during the three dry-year periods of high wholesale prices, in 2001, 2003, and 2006. The high estimated market rents in those years depends on an assumption that the very high prices persisting for months during these episodes had no effect on demand or consumption of electricity: they also adopt an approach to calculating marginal cost that does not properly take into account the effect that fuel and plant availability, reserve requirements, transmission constraints and risk has on the cost structures of firms. Partly this may be because of physical and institutional features of the New Zealand electricity market that, while not necessarily unique to New Zealand, are not standard in much of the world.

1 See, for example, Electricity Technical Advisory Group (2009), NZIER (2009), and University of Auckland (2009), 
In the following section, we describe these relevant features of the New Zealand market. In Section 3 we explain how these are relevant to the assessment of the market-rent calculations shown in the report's Figure 5.12.

\section{Figure 5.12: Decomposition of Wholesale Market Revenues, Counterfactual 2}

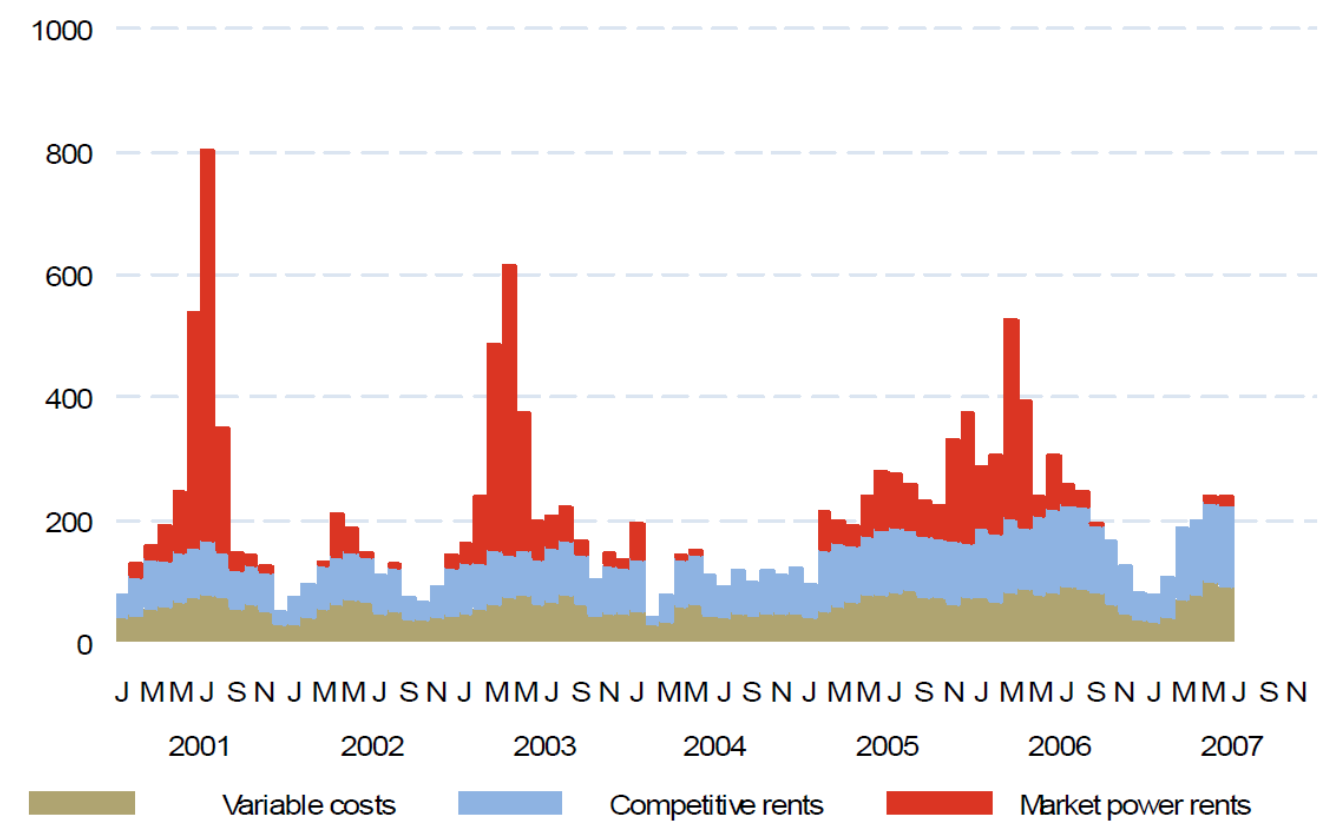

Source: Calculations as described in text using offer data from Centralised Data Set and EMS, dispatch data from $\mathrm{M}-\mathrm{Co}$, and fuel price and usage data from Contact Energy, Genesis Energy and MED.

\section{Relevant New Zealand Electricity Market Characteristics}

The structure of the New Zealand electricity market and its standing relative to other electricity markets, is set out by Evans and Meade (2005). The key relevant features are that it is an energy-only market, has volatile reservoir inflows and low storage capacity, volatile demand that is inelastic in the very short run, and vertical integration of retail and generation. 
In an energy-only market, the distribution of electricity prices over time, including peak, off-peak, and fuel-shortage periods must not only fund the operational costs involved in producing electricity, but also provide capital cost recovery to cover the cost of maintaining and expanding capacity. While other countries such as Australia and the UK have markets designed on a similar energy-only basis, in other jurisdictions, such as those generally found in the USA, a two-part payment approach is employed that typically, combines partial regulation of wholesale energy prices with either a separate market for capacity or an alternative capacity payment scheme. Where price caps in the primary energy market are designed only to permit recovery at the level of SRMC, capacity markets or payment schemes are necessary for capital cost recovery. In New Zealand, as well as in Australia (where the price cap is defined not in relation to the SRMC of peaking plant, but in order to achieve a certain reliability standard), energy prices in peak periods are expected to rise high enough, sufficiently often, to contribute a significant amount to cost recovery for all types of plant at all positions in the merit order.

Electricity demand must equal supply continuously at all points in time and space or massive disruption to electricity users and damage to electricity plant will result. Market operators achieve this by combining the bids and offers of participants with knowledge of the structure and limitations of the transmission network, while simultaneously providing reserve and other ancillary services. The predominantly one-dimensional network that is dictated by New Zealand's geographical features and the location of major generation relative to major load results in greater system security risks in contrast to more two-dimensional networks in which there are multiple paths by which power can move from one location to another.

The requirement for instantaneous reserves is satisfied by capacity held back from the energy market for use in the event that a generation or transmission failure occurs within the dispatch period. Reserves are particularly important in New Zealand because of the large size 
of individual generation units and of the high-voltage direct-current (HVDC) link connecting the North and South islands, relative to load. If the HVDC link fails, there is no other way for generation in one island to meet demand in the other, and each island, which is a separate AC system, must adjust generation accordingly. In New Zealand, instantaneous reserve markets are cleared in conjunction with the energy market, based on anticipated requirements determined in the pre-dispatch process.

Electricity markets have volatile demand, often brought about by fluctuations in weather conditions. The elasticity of demand follows the classic more that in the very short run, such as within a half-hour trading period, demand is very inelastic, but as the time frame extends demand becomes much more elastic. The elasticity of demand is endogenous to the market structure because, where price fluctuation is not reduced by price caps, instruments such as demand-side management options emerge to mitigate price volatility. ${ }^{2}$

The large share of energy provided by hydro generation (55-65 percent of total generation depending upon reservoir inflows) combined with low storage capacity (see the Electricity Technical Advisory Group (2009)) is a distinctive feature of the New Zealand market. This uncertainty requires that generation decisions must be based upon expectations about a risky future and not just current weather, demand and storage. This feature is important as it means that, for a substantial portion of generation plant, a large component of marginal cost — the the option value of a marginal unit of stored fuel—is volatile and not directly observable. ${ }^{3}$

2 If households are excluded from demand management, in New Zealand there remains $65 \%$ of demand available to raise price elasticity. In particularly severe dry years, household demand can be and has been affected by government conservation schemes.

3 Throughout this paper we use the term "fuel" to mean any form of stored energy used to generate electricity, and so it refers to water stored in hydro reservoirs as well as coal and gas. 
Finally, another key background feature of the New Zealand market is that it permits vertical integration of generation and retail. This too is the case in other countries, for example Spain, but it is not generally the case in the US, where vertical integration is commonly not permitted, although it does characterise some municipalities. Hogan and Meade (2007) argue that vertical integration does not accentuate market power by generators, and may mitigate it. This finding is broadly corroborated by the empirical work of Bushnell, Mansur and Saravia (2008). Vertical integration can be viewed as a substitute for generators entering long-term full hedge contracts. Both vertical integration and hedge arrangements can have the effect of materially reducing the impact of the spot market on participants. To put it simply, suppose that 80 percent of electricity is covered by hedge contracts and/or vertical integration. Then, for 80 percent of New Zealand's electricity, the wholesale spot price will not directly influence the price paid by final consumers at that time. ${ }^{4}$

\section{Overview: The Rent Calculation}

While we consider key aspects of Wolak's analysis in the separate papers that follow, it is informative to set out as an overview the basis of his "excess" rent calculation. It subtracts from the actual outcome (the factual) an estimated counterfactual series of prices.

The counterfactual prices are calculated by assuming i) a counterfactual series of marginal costs, ii) performance of the transmission grid, iii) plant availability, and iv) demand response. We consider each of these in turn.

4 The quantum of electricity that is hedged is private information, but Wolak was able to extract it using the compulsory information acquirement of the Commerce Act 1986: Section 98. It is thought that at least 80 percent of the electricity transacted is insulated from the immediate spot price. 


\subsection{Marginal Cost.}

For hydro operators, the marginal cost of generating electricity includes the option value of retaining water in storage for future use. Evans and Guthrie (2009), argue that generators can be viewed as achieving the optimal trade-off between the returns from storing water for future generation against the returns from generating now, by treating stored water as an asset. Hydro generators base storage and release decisions on the option value, or shadow price, of stored water in a dry year, taking into account firm characteristics such as the portfolio position, operational constraints and environmental caveats, as well as uncertainty about hydrological inflows and demand patterns. Taking these factors into consideration, the reservoir operator will store water if a future attainable use is expected to be more valuable than use in the current period.

The Wolak report does allow some consideration of option value in its calculation of marginal cost for hydro stations, but without appropriate consideration of the role of uncertainty. Consider the measurement of the opportunity cost of water in a hydro station. By assuming the optimal allocation of water to the highest value use, the report assumes that hydro station operators know in advance how prices will evolve over a season, so that the opportunity cost of water used to generate electricity now is the price that that power could be sold for later in the season. This approach ignores the impact of uncertainty and risk aversion. While the option value of water retained in a reservoir could be higher or lower than the expost realised value depending on actual inflow eventualities, when reservoir inflows are uncertain it will typically be higher as some water is retained by risk averse and overcontracted firms as insurance against extreme dry-year events.

In a perfectly competitive market, current and future trade-offs between hydro generation and substitute fuels have the effect of valuing water. Hydro offers are based on a variety of factors, as described above, which can be summarised by the perceived distribution 
of marginal water values. When the optimal dispatch is not constrained by plant capacity, transmission capacity, storage limits, and the availability of other fuel is not constrained at its market price, the shadow price of water in a deterministic world should, if we ignore the value of lost load, be capped by the marginal cost of the peaking technology, whether that be a generation plant or demand side management option. However, in practice these limits exist, and the world is uncertain so decisions may well be socially optimal when taken at an unobserved shadow price of stored water, that is (potentially much) larger than the observed or reported marginal cost of a peaking technology, and certainly much higher than the marginal cost of gas fired plant.

In contrast, Wolak implicitly assumes that the maximum marginal water value is the cost of gas as reported to him by the generators. The reporting was under the Commerce Act (Section 98) and we are not privy to it, but it would have been most unlikely to include shadow prices generated by fuel availability issues for these are volatile and vary over time and with the state of the market. ${ }^{5}$ In essence, the Wolak Report's perfectly-competitive benchmark counterfactual assumed that the opportunity cost of fuel used in thermal power stations is simply the replacement cost of that fuel, and that the opportunity cost of water in a hydro station is capped at the highest value in a season of the thermal-station, short-run marginal cost calculated using an assumed fuel replacement cost.

Energy and fuel limits are particularly important in New Zealand as gas and coal storage and delivery are also limited. If there is a shortage of hydro generation, gas and coal shortages will also be a possibility and generators will seek to eke out gas supplies based on the quantum stored, reservoir levels, and expectations of the future, much the same as for

5 Indeed, under take-or pay gas contracts, which exist in the market, the price per unit of fuel requires assumptions to estimate and does not have the meaning of a spot price for gas.. 
hydro management. ${ }^{6}$ In other words, for any fuel that is limited in supply, availability has to be managed just as it is for hydro. This is implied by "take or pay" fuel contracts that alone render Wolak's measure of marginal cost awry ${ }^{7}$ as under these contracts thermal stations are not able to access significantly more or less fuel according to the particular hydrological outcome of the year, and so need to husband their available fuel with an associated opportunity cost of use that exceeds simple replacement cost. In this circumstance the maximum marginal cost of electricity generation is not the price paid for gas. Instead, it is some higher amount that is not calculable independently of the current and future value of other fuels and demand side options. ${ }^{8}$ Thus, the calculation of the marginal cost of other fuels in Wolak's counterfactual is also not independently observable and is under-estimated.

Finally, it is important to recognise that investment in the electricity market would be limited under Wolak's counterfactual and marginal-cost estimation. In a SRMC-based energyonly pricing scheme (estimated as Wolak does), practically no firm would have the incentive to invest. ${ }^{9}$ Risk-averse investors require recovery of capital costs with a suitable premium for risk, as well as the fixed and variable operating costs they incur in operations. Pricing according to Wolak's short-run-marginal-cost standard limits the operating surplus available for fixed costs and capital recovery and therefore cannot support equilibrium investment. Where marginal cost includes the opportunity cost of scarcity and a suitable risk premium, investment is supported in an energy-only market. ${ }^{10}$ In this setting, firms will invest in

6 Constraints were factors in the high prices of the winter of 2001 when inflows had been very low and gas plants had to husband the availability of gas plants (Market Surveillance Committee, 2001).

7 The point remains, whether or not these contracts permit banking of gas.

8 The future prices of electricity set an upper bound to marginal cost. But without an independent measure of marginal cost, assessing the relationship between price and marginal cost for market power evaluation is fraught.

9 There may be some partial incentives where operating surplus is produced: e.g. if marginal cost is increasing, or if the price of electricity is sufficiently above the marginal cost of new plant. This latter possibility is not an equilibrium position.

10 This point goes back to Baumol and Bradford (1970). 
additional plant when the marginal cost and frequency of scarcity, whether generated by energy or capacity concerns, generates sufficient operating surplus to justify new plants. The prices generated by Wolak's counterfactual will not support this criterion. If electricity prices were to equal those in Wolak's counterfactual, the frequency of shortages would increase unless intervention on a non-commercial basis occurred. High prices during scarcity periods are essential to pay for all capacity and provide an incentive for investment in new capacity.

\subsection{Transmission.}

Wolak uses bivariate correlations of prices at different locations to conclude that New Zealand has "one market" as opposed to regional markets; and thus that plant has access to the entire market no matter what location it is in. ${ }^{11}$ But even if statistical analysis suggests that the electricity market is one market most of the time, there are periods in which transmission constraints have a material influence on the dispatch process and create price differentials. The effect of transmission constraints, which may be relatively modest most of the time, is exacerbated when combined with real or anticipated fuel and plant availability issues if generators suspect they will not be able to physically hedge loads in different regions or even worse suspect there will be an actual shortage unless fuel is conserved within a particular island. In a typical dry year in New Zealand, the reality of the HVDC link being at full capacity in particular scenarios is priced into the value of water, and hydro producers will conserve greater quantities of water than they would if the link was unlimited. The effect of this measure is to increase water values, resulting in the use of alternative generation, which helps assist a severe crisis in the same way demand response does. Whether or not the crisis eventuates, the possibility of the crisis must be considered. Further evidence that the

11 The bivariate approach is inferior to consideration of regional markets jointly. Evans, Guthrie and Videbeck (2007) use a principal components approach and find the same result as Wolak to 2006 across 7 nodes considered jointly. 
vertically integrated firms believe transmission constraints to be a significant issue is the geographical market structure of the firms, each hedging their own retail base with nearby generation. This would not be necessary if the market were consistently a nationwide market.

The long thin nature of the New Zealand transmission network makes the likelihood of bottlenecks more likely than in a network with a more two dimensional structure. The New Zealand system relies heavily on a high voltage direct current link (HVDC) between the north and south islands, which connects two otherwise separate AC networks. Apart from the considerable reserve issues this presents, the limit on transmission between islands does in itself place restrictions on the optimal dispatch of generation plant. This results in transmission constraints that invalidate the water allocation mechanism used in the Wolak report, and necessarily reduces the ability of hydro generation to smooth marginal costs throughout the period of the study.

\subsection{Plant Availability.}

The Wolak counterfactual also assumed greater utilisation of existing plant capacity than had been the case in the factual, arguing that there was excess capacity to such an extent that prices should be equated to the counterfactual's marginal cost. The report claimed that, at all times in the period of the data being considered, total output from all power stations was considerably less than the implied capacity derived by considering the sum of the maximum output of each individual station over the period in question. This conclusion of permanent excess capacity does not consider the already-mentioned issues of fuel availability or transmission constraints, and also ignores the implication of ancillary service requirements, all of which may restrict plants to generate below their rated capacity.

The New Zealand wholesale market combines a market for power, with other markets and schemes to provide ancillary services. Most notably there are two classes of instantaneous 
reserve, as well as a frequency-keeping role that need to be provided for. Reserve provision is relatively less important in larger two dimensional networks, which by virtue of their size and geographical shape, are less susceptible to adverse effects from transmission failure. Because the NZ transmission network features an HVDC link which joins two separate AC networks, the traditional $(\mathrm{N}-1)$ reliability standard has to be augmented to include inflows from the other island as a potential source of failure to be considered, along with the largest generation in each island at any given time. As plant operations vary and power sometimes flows north and sometimes, albeit less frequently, south, the amount of capacity required for reserve in each island will necessarily fluctuate over time. The quantity of reserve required in each island depends on the dispatch of plant in different locations, and it is possible that reserve requirements in one island can exceed generation in that island.

In periods of system stress with fuel shortage and constrained HVDC transfers, the reserve requirements in the receiving island can be particularly onerous. Wolak's analysis of excess capacity does not imply that the apparent excess capacity is actually excess and therefore does not imply that we should expect a competitive market to yield prices equal to short-run marginal cost. ${ }^{12}$

\subsection{Demand Response}

Independently of issues surrounding marginal cost estimation, the effect of the transmission network, and the effect of ancillary services requirements, elastic demand would yield contractual and/or spot market consumption responses to high prices and mitigate increases in marginal costs in times of fuel and plant scarcity. The counterfactual of the Wolak report rejected this possibility and assumed that demand is perfectly inelastic, ignoring

12 The Market Surveillance Committee (2001) report that this occurred in the winter of 2001. 
the implications of sustained high prices for both spot market purchasers as well as any possible demand-side management options. This may be a more reasonable assumption when describing the performance of the market in the very short term, such as unanticipated brief shocks to supply within a half-hour trading period, because with sellers submitting supply offers every half-hour, and buyers simply drawing as much power as they wish, the market price is realised ex post to equate aggregate demand to aggregate supply at each node, giving very little opportunity for response. In fact, because of the basic structure of market clearance, in the short term, demand is insensitive to price as participants are not even able to easily calculate the price before using the power even if the wished to do so. ${ }^{13}$

But the general nature of energy crises in NZ is that there is a shortage of hydro inflows, and this energy shortage develops over a period of several weeks or months in a dry year, so that demand can and does have the opportunity to respond to actual and forecast increases in the wholesale price in a variety of ways. First, there is a small percentage of the final demand that buys directly from the wholesale market and so has an incentive to reduce demand when prices rise. Second, it is profitable for hedged parties to put electricity back into the market rather than consume it when prices are high. Third, retail companies offer financial incentives to customers to reduce demand. Finally, in the past, and certainly within the study period of the report, the threat of supply shortages has led to government-sponsored conservation campaigns, which have achieved significant consumption reductions. For all the above reasons, there were demand responses in the high price episodes of Figure 1 and this was precisely because of the high prices experienced in these episodes. Using the same transacted quantity in the factual and counterfactual implies either a) high prices resulting from the claimed exercise of market power resulted in no social inefficiency, just a largely internal

13 Although, as pointed out above, mechanisms can be instituted that engender some intra-trading-period demand response. 
transfer from the retail to the wholesale arms of vertically integrated gentailers, or b) the dispatch implied by the counterfactual would be insufficient to fulfil the demand that would have arisen from the proposed lower prices in his counterfactual. In the second case, shortages are implied, and in this scenario these should have been valued and included as a cost in the counterfactual at the value of lost load. The irony of the report and its view of New Zealand's power crises is that precisely because generators, both individually and collectively, do consider the potential cost and risk of shortages in dry years, they raised prices accordingly, and as a result the crises were largely avoided in the period of the study.

\section{Summary}

These four critiques and the fact that the rents only appear at times of fuel scarcity overwhelmingly point in the direction that the estimate of overcharging attributable to market power in the Wolak report is too high ${ }^{14}$, but they don't provide an alternative measure. There remain the other strands of argument and empirical evidence in the report that Wolak holds to be consistent with the high prices in dry years being the result of market power. This leads the authors of the NZIER discussion document prepared for the Major Electricity User's Group (NZIER, 2009), to comment:

Wolak's analysis has drawn a lot of criticism, not all of it valid. Most criticisms have been directed at the way in which he constructs competitive benchmark prices and thereby estimates market power rents. Criticism of this additional step in his analysis does not detract from the earlier steps in his methodology of examining the slopes of residual demand curves to determine ability and incentive to influence market clearing prices. This basic methodology is well-established and widely recognised and applied worldwide to assess competition in short-term wholesale markets.

14 Of course for the excessive prices to affect consumer welfare their effect on retail and hedge prices would have to be assessed. 
In the papers that follow, we turn our attention to these measures of the ability and incentive to exercise unilateral market power. We explain that even the concession of the NZIER statement is not warranted or even accurate; for we show that the methodology has no logical basis as it is specified and applied in the Wolak Report. In consequence, the approach is not applicable in the assessment of energy-only electricity markets. Whether a modified version of the approach is useful for other electricity markets would depend on the specific structure of those markets.

Finally, it is important to note that the key policy question is not whether electricity companies have been able to earn any non-competitive rents, but rather whether the level of any such rents are sufficient to imply that a policy response is warranted and, if so, what that response should be. The overall conclusion of the first three papers in this symposium is that the Wolak report presents no convincing evidence that there is a problem with the exercise of market power in the New Zealand wholesale market. There may be improvements that can be made to promote the well functioning of this market, but such policy changes would need to be considered carefully, and should not be motivated by the headline value of $\$ 4.3 \mathrm{~b}$ presented in the Wolak report.

\section{Afterword:}

The editor of this journal made available to us Browne, Poletti and Young (2011), which simulates the New Zealand electricity market and finds market rents of the order of $\$ 2.6$ b, during 2006 and 2008. Among other things its approach ignores central points of our papers reported here. It simply does not provide a basis for quantifying the existence of rents. We select three issues.

First Browne, Poletti and Young op cit (BPY) assume that demand is perfectly inelastic which accentuates the potentiality for market power. In fact demand is not 
perfectly inelastic even within a trading period and over longer periods of the sort experienced in dry years it is more elastic.

Second, BPY calibrate behavioural parameters of their model in a wet year and use the same parameters in a dry year. There is no reason to believe that gas generators, for example, would or could behave the same way in a dry year as a wet year as the thermal generation marginal cost curve is increasing and will reflect efficiency and the availability (option values) of gas as well as its price. Furthermore, the extent to which vertically integrated generators have a net positive or negative position in the wholesale market (and hence their incentive to exercise market power) can vary between wet and dry years simply because hydro makes up a much larger fraction of the generation capacity of some firms than it does others.

Third, the BPY model produces peculiar behavior. BPY (p.12) state "Market power does not increase dramatically during the period when lake levels are low. On average it is highest when demand is high. This result is dramatically different to that of Wolak and is a result of us using very different water values to those that Wolak uses. Recall that he effectively uses marginal thermal prices as the opportunity cost of water. If we were to use the same values for water as Wolak did our simulated prices would be considerably off'. At the conceptual level Wolak in this case is right: gas and hydro generation are substitute producers of electricity and in an oligopolistic market it will general be the case that the marginal cost of electricity produced by gas and water will be the same (see also, Evans Guthrie and Lu (2010)).

Overall, BPY find that including the option value of water increases the estimated marginal cost of production in dry years and correspondingly reduces the estimates of market rents during periods of water scarcity. They also find higher levels of market rents during periods of relative water abundance, suggesting estimates of marginal cost 
that are much lower than Wolak's in those periods. We believe these results are counterintuitive and highly sensitive to the issues raised here. 


\section{References:}

Baumol, William A. and David F. Bradford (1970), “Optimal Departures From Marginal Cost Pricing", American Economic Review, 60(3): 265-83.

Browne, Oliver, Stephen Poletti1, and David Young, (2011)," Simulating market power in the New Zealand electricity market” draft 17 May 2011 marked for peer review, 17pp.

Bushnell, J., E.T. Mansur and C. Saravia (2008), "Vertical Arrangements, Market Structure, and Competition: An Analysis of Restructured U.S. Electricity Markets," American Economic Review, 98(1): 237-66.

Electricity Technical Advisory Group (2009), "Improving Electricity Market Performance”, August. Retrievable at http://www.med.govt.nz/upload/69725/volume1.pdf.

Evans Lewis, Graeme Guthrie and Steen Videbeck (2007), “Assessing the Integration of Electricity Markets using Principal Component Analysis: Network and Market Structure Effects", Contemporary Economic Policy, 26(1) (2007): 144-61.

Evans, L. and G. Guthrie (2009), "How Options Provided by Storage Affect Electricity Prices," Southern Economic Journal, Southern Economic Association, vol. 75(3): 681702.

Evans, L. and R. Meade (2005), Alternating Currents or Counter-Revolution? Contemporary Electricity Reform in New Zealand, VUW Press, 346pp.

Evans, L., G. Guthrie, and A. Lu (2010), "A New Zealand Electricity Market Model: Assessment of the Effect of Climate Change on Electricity Production and Consumption”. http://www.iscr.org.nz/f585,16761/16761_NZ_Electricity_Market_Model.pdf 
Hogan, S. and R. Meade (2007), "Vertical Integration and Market Power in Electricity Markets", Working Paper, New Zealand Institute for the Study of Competition and Regulation. Retrieved from $\underline{h t t p: / / w w w . i s c r . o r g . n z / n 300,53 . h t m l}$.

Market Surveillance Committee, Claimed "Undesirable Situation” arising from High Spot Prices in May/Jun 2001, Report to the New Zealand Electricity Market, 17 June 2001. $37 \mathrm{pp}$.

NZIER (2009), “Improving Electricity Market Performance Discussion Document's Comments on Wolak's Analysis", Report to the Major Electricity User's Group, September. Retrieved from www.meug.co.nz/includes/download.aspx?ID=105517.

University of Auckland Energy Centre and University of Auckland Electric Power Optimization Centre (2009), “A Response to the Wolak Report”. Retrieved from http://www.esc.auckland.ac.nz/epoc/A $\% 20$ Response $\% 20$ to $\% 20$ the $\% 20$ Wolak $\% 20$ Report .pdf.

Wolak, F. (2009), “An Assessment of the Performance of the New Zealand Wholesale Electricity Market", Report for the Commerce Commission. Retrieved from http://www.comcom.govt.nz/investigation-reports/. 